\title{
Corporate innovation ecosystems: challenges and opportunities
}

\author{
Dmitrii Shevchuk ${ }^{1, *}$, Igor Ilin $^{1}$, Victoria Iliashenko ${ }^{1}$, and Alissa Dubgorn ${ }^{1}$ \\ ${ }^{1}$ Peter the Great St.Petersburg Polytechnic University, 29, Polytechnicheskaya str., 195251, St. \\ Petersburg, Russia
}

\begin{abstract}
This article proposes to consider the concepts of an innovation ecosystem and a digital platform. The analysis of world experience in terms of corporate innovative ecosystems contributing to the accelerated implementation of innovations is presented. The article focuses on corporate innovation ecosystems, gives their definition and key functions. The analysis of the management of innovative ecosystems in the world and in Russia is given. Describes the ecosystem approach and the structure of the corporate innovation ecosystem. As part of the study, it is planned to form a scheme for organizing a corporate innovation ecosystem, considering the place of digital platforms in the entire ecosystem.
\end{abstract}

\section{Introduction}

Currently, the priority area of economic development is the transition from raw materials to innovative high-tech development.

The development of the economy at the present stage is determined by the following trends [1]:

- the world economy is undergoing a transition from an industrial economy to an information economy;

- competition has increased due to economic liberalization;

- in the conditions of information transparency, the emphasis on design and engineering allows you to create a more successful and competitive product;

- car sharing services and other Internet services allow you to abandon personal cars and other goods and services, which leads to a decrease in their consumption, and the rise of Renting Economy ensures, in an unstable economic situation, not only frugality, but also environmental awareness;

- the growth in the number of breakthrough innovations, that is, products and services that meet the demands of the information age - this is the ideology of the economy of the future. They require completely new approaches to work, tools, and culture;

- reducing the role of securities of the largest and most stable operating companies ("blue chips"), since in the process of economic evolution their place is taken by startups.

Recently, the creation of conditions for sustainable innovative development of the economy is associated with the formation of an innovation ecosystem. It describes the

\footnotetext{
* Corresponding author: dmitrii.shevchuk@gmail.com
} 
modern model of innovative development of the economy of a region or country and, in fact, is an up-to-date version of earlier concepts, the first and foremost of which is the theory of the national innovation system [2].

The concept of an innovation ecosystem was proposed by Charles W. Wessner in 2004 and is a tool for creating conditions that increase the competitiveness of organizations in national and regional economies [3]. At the center of the concept is the idea of innovation as a process of transforming scientific research into a marketable product or service, which requires a lot of collective efforts of participants: companies, universities, research companies, venture capital funds and similar funds. An innovation ecosystem shapes these efforts to create synergies.

The term "innovation ecosystem" synthesizes two key concepts: "innovativeness" and "ecosystem".

An ecosystem is a complex (according to L. Bertalanffy's definition of complex systems) self-organizing, self-regulating, and self-developing system. The ecosystem is an open system and is characterized by input and output flows of matter and energy [4]. According to GG Vinberg's definition, an ecosystem (from the Greek oikos - dwelling, residence) is a natural complex formed by living organisms and their habitat (soil, reservoir, etc.), interconnected by the exchange of substances and energy.

An ecosystem of innovations is an environment formed directly by the participants in the innovation process, in which their interaction takes place, aimed at creating and developing innovations.

Thus, an innovation ecosystem can be understood as a self-organizing, self-regulating, and self-developing, open system characterized by input flows of ideas, value, people, information, resources. In this sense, an innovation ecosystem is an economy in which specific subjects of economic and social relations operate [5]. The difference between an innovation ecosystem is that it produces innovations, ideas, intellectual property and people for society and other industries, which in response give the ecosystem problems and demands, as well as resources for self-development. An ecosystem cannot exist without a global economy, since it is from it that the demand for innovations and changes comes, and a global economy without an ecosystem is doomed to stagnation and degradation, because IES accumulates a key creative resource [6].

Innovation ecosystems are based on innovators or innovative individuals - those who create, develop, and promote innovation based on their own motivation or on the basis of demand. In addition to innovators, innovation ecosystems include various agents that help innovators - investors, corporations and foundations that finance innovation. There are two defining directions that support IES - the flow of innovation and the flow of demand for innovation.

Accordingly, all IES participants can be conditionally divided into two categories those who create demand for innovations and those who create innovations themselves. Today, seven types of ecosystems are distinguished [7]:

- World innovation ecosystem.

- National innovation ecosystems.

- Regional ecosystems.

- Local innovation ecosystems (Technopolises).

- Corporate (industry) innovation ecosystems.

- Entrepreneurial innovation ecosystems.

- Ecosystem of an innovative individual.

Within the framework of this study, the authors focus on corporate innovation ecosystems.

The corporate innovation ecosystem develops on the platform of open innovation theory, public-private partnerships as a system of government support and risk sharing for 
innovative projects, organizing research activities within corporations and creating a network of small innovative enterprises. Open innovation presupposes a constant search for new competencies for innovative projects, which are best carried out outside corporations, through partners, interaction with universities, attraction of innovative companies (startups) for implementation based on the preliminary establishment of conditions for the ownership and use of intellectual property [8]. As a rule, the research activities of corporations are organized through parent companies, spinoffs, while the companies participate in the educational processes of universities, presenting the processes of improving technologies based on the knowledge gained.

The key functions of corporate innovation systems are almost identical in Russian and foreign corporations and include the following components:

- collection and preliminary analysis of innovative ideas; general organization of the R\&D process;

- search for potential clients, customers of innovative products and solutions; analysis of the company's innovative capabilities;

- incubation of early-stage projects;

- managing a portfolio of innovative projects and maintaining a balance in it between projects aimed at long-term development and those aimed at improving the current performance of the company;

- introduction of new technological processes and mechanisms for accelerated commercialization of innovations; assessment of the effectiveness of the implementation of innovative projects [9].

Views on the essence of innovation and how they could be facilitated may differ, but the underlying postulate is that innovation occurs when ideas find the conditions for implementation. Naturally, in practical application, detailed clarifications become decisive where ideas can be born, who will undertake to implement them, what infrastructure is required, why high-risk projects are promising and how to bring all the elements together into a system. The main goal of this research is forming a scheme for organizing a corporate innovation ecosystem, considering the place of digital platforms in the entire ecosystem.

\section{Materials and Methods}

The study used the following methods:

- General scientific research methods.

- Comparative analysis methods.

- Methods for modeling the architecture of digital solutions.

For literature overview sources from various conferences, books from electronic libraries and websites were used. The study of specialized literature helped the authors to carry out a comparative analysis of the leading practices of using corporate innovation systems by industry.

After analyzing the terminological base of innovation ecosystems, the relationship between digital platforms and the corporate innovation ecosystem was proposed. The methodology for creating a scheme is to analyze their interaction, identify the key components of the innovation ecosystem. 


\section{Results}

\subsection{Comparative analysis of the management of innovative ecosystems in the world and in Russia}

Among foreign companies, an approach has become widespread, associated with a clear distribution of budgets for innovative projects between three areas of investment: in the improvement of existing products and processes; search for related technologies and solutions; funding research on fundamentally new, breakthrough technologies ("rule 7020-10" or similar ones). In the practice of Russian companies, approaches to such a clear structuring of costs have not been found. Russian companies underestimate the effectiveness of setting up temporary design laboratories in addition to traditional R\&D centers. If the latter are focused on the development of technologies traditional for the company, then innovation laboratories can quickly implement a project and test promising new directions for the company. For example, Rolls-Royce's "innovation cells", which focus on the rapid development of ideas and the accelerated creation of new business applications, typically last no more than 90 days. This practice is quite common in foreign companies [10].

In recent years, foreign companies have begun to actively work towards the creation of so-called technological platforms. Direct access by multiple users to such platforms allows for a combination of high aggregate supply and demand with the convenience of services, as well as, most importantly, with a significant reduction in transaction costs. Almost all companies leading in global innovation rankings are actively using various platforms to gain accelerated access to external resources and data sources, which they then seek to include in the process of developing new corporate business models or products and services. Russian companies are just starting to work in this direction [11].

In terms of the development of digital technologies, the most advanced foreign companies have come to understand the need to form a hybrid organizational structure that unites a team of digital specialists with a business team from the central management office. In many Russian companies, the digitalization process is still the domain of IT specialists, which does not allow to fully unleash the potential of digital transformation and use all its possibilities [12]. An important problem of large Russian business, both public and private, is the absence in its plans of truly large-scale, breakthrough technological projects, which emasculates its innovative strategies. Only a small number of corporations have taken the positions of global technology leaders. In the case of state-owned companies, the state could engage in setting breakthrough tasks, which has already been done in part by appointing a number of corporations to them responsible for the development of promising areas.

\subsection{Literature overview}

This chapter provides an overview of the various industries and an analysis of the extent of their technological innovation.

\subsubsection{Energy Industry}

The specificity of Gazpromneft is the production from multiphase fields and development of the Arctic offshore; innovations will help to develop this specificity into a competitive advantage [13]. 
Gazpromneft develops an innovative ecosystem, acting in many directions. Examples from open sources can be cited - development of corporate technoparks in Omsk and St. Petersburg, Polytechnic School at Tumen, Research and Educational centre in St. Petersburg Polytechnic University, implementation of the ERA Strategy, foresight analysis of the industry, R\&D with leading Russian universities (St. Petersburg State University, MIPT, Moscow State University, SkolTech, Gubkin Russian State University of Oil and Gas, Mining University, Boreskov Institute of Catalysis), holding open innovative ideas contests (for example, SmartOil Contest).

\subsubsection{Transport Industry}

Transport innovation is the introduction of new knowledge, improvement of technologies aimed at solving social and environmental problems, increasing productivity, and reducing production and time costs in the transport system [14].

Areas of innovative transport ecosystems include:

- Transition of the transport system to a more developed technological level of freight and passenger transportation, including competent automation, informatization and electronicization of all departments of the transport system in the link "passengers / cargo management".

- Moving away from the automation of individual processes to absolute automation to reduce the cost of manual labor and time costs. Ignoring this task lowers profits and reduces competitiveness due to low labor productivity.

- Improving efficiency and reducing the cost of transportation. Creation of environmentally friendly transport, endowed with the potential to organize bullet traffic.

\subsubsection{Healthcare Sphere}

The last few years have become significant for medicine: the introduction of high technologies has brought healthcare to a new - digital - level. The current "digital medicine" is not only an electronic appointment or online consultation with a doctor, but also the use of new generation systems using the capabilities of artificial intelligence, the Internet of things, augmented reality, BlockChain, etc. All these technologies work today to improve the quality and availability of medical services while reducing financial costs [15].

The peculiarity of medicine is that there are not many radical (breakthrough) technological innovations that are born in the laboratories of medical research centers. Most new medical technologies are based on discoveries and inventions in other fields that have been borrowed or adapted to medical needs, such as electronic diagnostics, lasers, ultrasound, magnetic resonance, etc.

Today, players of different levels come to the domestic digital healthcare market - from startups to leaders of the Russian IT industry (Yandex, Mail.ru). Among them is Philips, a world-renowned health technology expert.

Philips has a wealth of experience in digital health developments and the ability to address the main challenge of digital health - to create systems that seamlessly integrate IT solutions into healthcare and adapt innovative technologies for medical needs. Working closely with the world's leading healthcare providers, Philips brings together physicians, patients, external digital services and technologies into one coherent ecosystem, which is now one of the key focuses of the company in further developing its solutions for the healthcare industry.

The creation of such integrated systems makes medical care more accessible and of high quality, which is especially important for Russian regions - thanks to digitalization, a doctor 
from anywhere in the country can get advice from experts from central clinics by sending the patient's research results via "intrasystem communication".

\subsubsection{Education sphere}

It should be noted that there is no fundamental possibility of an unambiguous formulation of the rules for creating a technological ecosystem. For example, in the early 2010s, there was a discussion about choosing a model for an R\&D centre for the Skolkovo project: two models were proposed - centralized and network based on "anchor" institutes; as a result, the centralized Skolkovo Institute of Science and Technology (SkolTech) was created. But the discussion on this topic continues, today Russian companies choose different models when creating corporate R\&D centres (see examples of Russian Railways, Norilsk Nickel and Sberbank). Further, on a global scale, the North American model assumes a large amount of "smart" money from private investors, China has built a deeply echeloned system of state support for innovation, Europe is also "going its own way [16].

Numerous federal development institutions - Russian Venture Fund, the Skolkovo project, RosSEZ, VEB, industry development institutions - RosKosmos, RosAtom, RusNano, etc. can be considered as benchmarks in certain areas. In St. Petersburg, the Ingria technopark and clusters of innovative companies in biomedical and IT domains are to be considered.

\subsection{Ecosystem approach and structure of corporate innovation ecosystem}

The ecosystem approach considers innovation systems at all levels (national, regional, etc.) as a dynamic set of organizations and institutions together with a mobile set of their multidimensional internal connections [17]. According to one of the interpretations, it includes economic agents, their relationships, as well as an innovative environment consisting of ideas, technologies, rules of the game, social interactions and culture. The ecosystem approach to innovation policy puts forward several principles important for economic policy that are at odds with the assumptions of a static systemic model. First, if static systems can be regulated exclusively by the method from above, through the influence of the state on organizations and institutions, then the ecosystem has its own market mechanisms of self-development, that is, it is controlled by the method from below, which creates the prerequisites for the continuity of innovative processes, eliminating excessive government intervention ... Secondly, the ecosystem approach focuses not so much on the participants in the system themselves, but on the nature and dynamics of their interactions.

An important stage in comprehending the practical experience of the past and formulating advanced approaches for future developments was the concept of "open innovation" by Henry Chesbrough [18].

It is becoming more and more difficult to solve complex technological problems alone. External conditions set the vector of sectorial development and formulate common tasks that can only be solved by consortia of participants with complementary competencies.

The ecosystem of technological innovation is composed of multiple elements [19] that can be grouped as follows (Figure 1):

- Ideas. Universities, research institutes and corporate R\&D centres are fertile environments for generating ideas. In the Russian scientific community, there are still a lot of young, ambitious people with breakthrough ideas (Flerov of our time). The ideas discussed today in the academic environment will tomorrow drive significant changes in the economy. 
- Participants. It is important to ensure the involvement of participants with complementary competencies in the project - academic theorists and practitioners with a broad scientific outlook, experienced engineers, technology brokers, representatives of the financial sector, officials responsible for making investment decisions. In an academic environment, the focus should be on young graduate students (think of the students of William Shockley). Success stories and corporate culture remain the main source of motivation. Acceleration programs help to complement the existing competencies in the teams.

- Investments. Innovative projects require adequate funding at different stages stimulating corporate programs, university and regional grants for spinoff projects at the initial stage, business angels' or industrial partners' investments in startups at the stage of product launch (business angels and industrial partners also bring practical experience to the projects), long-term investments from corporate, national and international venture capital funds to scale production and expand into the global market.

- Infrastructure. Similarly, at different stages of the project, adequate infrastructure is needed - discussion clubs and co-working spaces that facilitate open and informal communication, office space for startups, centres for the collective use of expensive equipment and prototyping centres, technoparks, technology transfer centres and foresight centres that provide consulting services, infrastructure for networking events. Digital infrastructure also plays an important role; the development of "knowledge management systems" has become a modern trend.

- Communications. For the constant circulation of ideas, maintaining and building new connections between the participants, a systematic approach to conducting networking events is required - forums, conferences and meetings that also involve communication without protocol. Media promotion raises the awareness of participants about current technological developments and the demands of the economy for innovation.

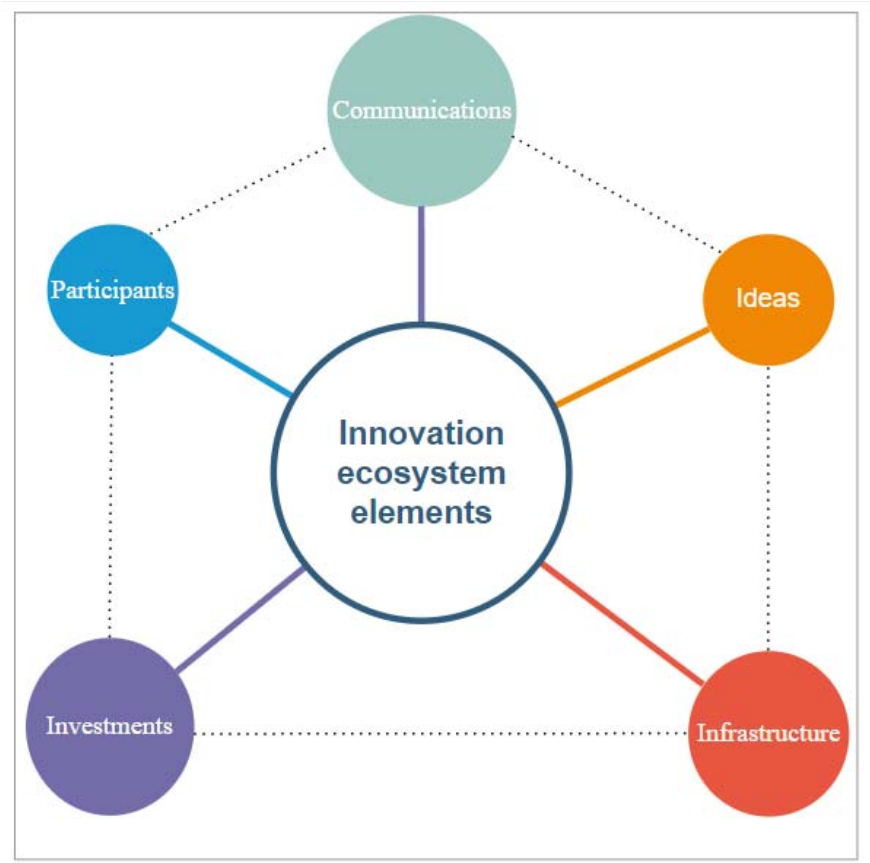

Fig. 1. Elements of the innovation ecosystem. 
The number of groups listed above and the criteria for the distribution of ecosystem elements between groups are rather arbitrary. The Ishikawa diagram, or the $5 \mathrm{M}$ diagram, named after five groups of elements, that capaciously describe any process - Man, Machine, Method, Material, Money, was taken as a methodological basis. In adapting this model to the description of the ecosystem, a straightforward logic was used. "Ideas" are the material from which motivated and competent "participants" based on a developed "infrastructure" by the "communication" method and by attracting long-term "investments" as a result receive innovations [20].

As benchmarks in the ecosystem development, the author proposes to consider technological clusters of universities in California and Massachusetts, EPFL and ETH technology parks (Lausanne and Zurich, Switzerland), the Skolkovo project, the experience of the Chinese Jiangning Development Zone and other examples.

When considering these examples, it is interesting how elements within groups and groups interact with each other; in other words, how these elements fit into the system. An important addition will be a warning against a formal approach. Copying elements of a successful ecosystem does not necessarily lead to the desired result. There is a joking adage that $5 \mathrm{M}$ describes any process in the detail required to copy this process, but often a process "reassembled" in other conditions does not work without the sixth component - Magic [21]. For example, there are ongoing discussions about the effectiveness of copying the experience of Stanford and Silicon Valley in other countries. The French Sophia-Antipolis project, the Russian Skolkovo project or other examples are obviously successful to the extent that they were able to consider the specifics of the region and current challenges.

Having analyzed the general structure of the innovation ecosystem and the practice of their implementation in various industries, we can single out a list of tools for building innovative ecosystems:

- R\&D-centers.

- Knowledge management systems.

- Systems to stimulate invention and innovation.

- Corporate entrepreneurship.

- Creation of spin-off companies for the implementation of innovative projects.

- $\quad$ "Single window" for interaction with external developers.

- Corporate technology parks.

- Corporate venture funds.

- Corporate acceleration programs.

- Open competitions for innovative projects.

- Interaction with scientific and educational organizations.

- Participation in technology alliances and consortia, international collaborations, and projects.

\subsection{Digital Platforms and corporate innovation ecosystems}

The digital platform is a key tool digital transformation of traditional industries and markets, the central concept of the global digital agenda delimiting digitalization strategies (digital automation) and digital transformation. Единая цифровая платформа строится вокруг концепции «озера данных». The digital platform of the innovation ecosystem allows [22]:

- perform scenario calculations of the development of the technological direction;

- mapping value chains, providing market participants with a holistic picture of economic ties;

- design optimal "Supplier - Consumer" relationships; 
- identify promising areas of development (growth drivers) for the creation of new businesses, products, services;

- to form the justification of investment projects for the production and introduction of products and services to promising markets.

To achieve economies of scale and focused market launch of new products, the digital platform helps to organize the structured work of a team of experts on the development of the supplier / consumer network and - identification and development of technologies, priority for the entire supply chain.

Using a digital platform allows you to reduce the risks of investment projects, attracting a network of international partners to create a new product for target foreign markets. Working with the model reduces the time for small companies to start selling a product or service, and for large companies it reduces the risks associated with organizing purchases [23].

The digital platform is formed in two stages [24]:

1. Building a digital model of Product Space (value chains).

a. Mapping value chains (Supplier - Consumer chains).

b. Identification of promising areas of development (growth drivers) for the creation of new businesses, products, services.

2. Building digital models of market supply (value proposition) in promising areas (growth drivers).

a. Selection and justification of the parameters of products/ services with the best market prospects, including in target foreign markets.

b. Selection and justification of technologies or equipment that are necessary to produce products / services.

c. Determination of the sufficiency of the skills and abilities of the company's employees to produce a product or service.

d. Determination of investment needs and funding sources for a project to bring new products and services to the market.

\subsection{Common results}

As part of the research results, the authors propose a scheme for the interaction of key components of the corporate innovation system and digital platforms.

The expansion of the principles of open innovation is a key feature of the current stage of the formation of corporate innovation systems in Russia. According to them, companies are looking for the best ways to obtain new solutions not only through traditional corporate R\&D departments, but also through active work with external sources of innovation, as well as enhancing the entrepreneurial potential of their own employees.

The result is not only getting innovative solutions, but also creating a favorable environment for the development of innovations within and around the company. A developing ecosystem with positive feedback is emerging as the number of participants grows and connections develop between them, conditions are created for the emergence of products and technologies necessary for the company, the successful application of which causes an influx of new participants. The efficiency of such an ecosystem increases as it grows and becomes more complex, its maturation takes time, so it is not enough to limit oneself to one-time bright events and experimental approaches to the topic. 


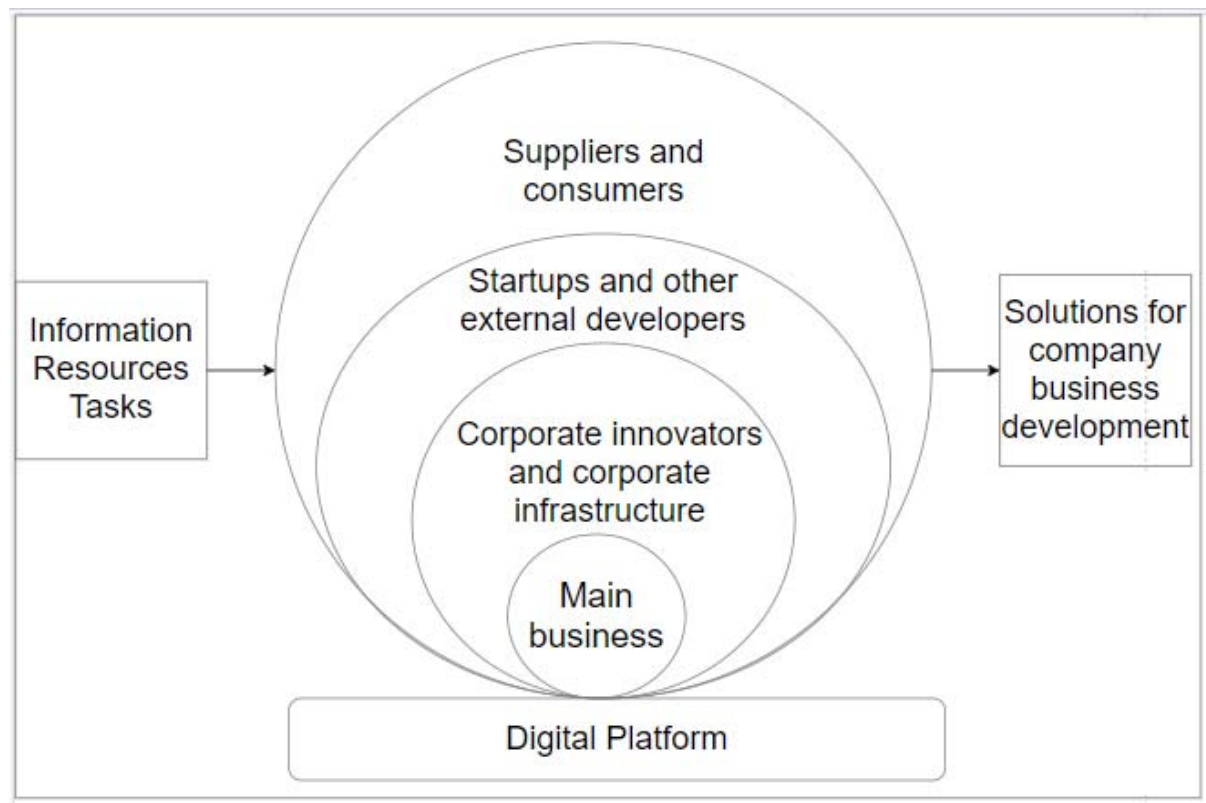

Fig. 2. Scheme of organization of corporate innovative ecosystem.

\section{Discussion}

The results of this study will lay the foundation for the formation of an integrated architecture of the corporate innovation ecosystem based on digital platforms. In the future, it is planned to scale the general scheme by industry to ensure an effective digital environment, depending on the specific needs of the industries. This will allow technology to evolve in line with stakeholder requirements.

\section{Conclusions}

In this article, the key concepts of a corporate innovation ecosystem and a digital platform. The analysis of the world experience of creating corporate innovation ecosystems in various industries: energy, transport, medicine, education. The key functions of corporate innovation systems were considered. Comparative analysis of the management of innovative ecosystems in the world and in Russia was one of the research parts. Described the ecosystem approach and the structure of the corporate innovation ecosystem. A list of tools for building innovative ecosystems was highlighted. Regarding digital platforms, the main functions were analyzed and the steps for its formation were described. As a result, the Scheme of organization of corporate innovative ecosystem was formed, considering the place of digital platforms in the entire ecosystem.

\section{Acknowledgments}

The reported study was funded by RSCF according to the research project № 19-18-00452. 


\section{References}

1. Factors and models of formation and development innovative ecosystems, https://www.hse.ru/data/2012/05/31/1250851792

2. Innovation Ecosystems vs. Innovation Systems in Terms of Collaboration and Cocreation of Value, https://core.ac.uk/download/pdf/77240101.pdf

3. S. Zmiyak, E. Ugnich, P. Tranov, Development of a Regional Innovation Ecosystem: The Role of a Pillar University. Growth Poles of the Global Economy: Emergence, Changes and Future Perspectives, 567-576

4. Systems theory, https://complexsystemstheory.net/systems-theory/

5. S. Maydanova, I. Ilin, Proceedings of the 33rd International Business Information Management Association Conference, IBIMA 2019: Education Excellence and Innovation Management through Vision 2020, 8818-8833 (2019)

6. V. Orlova, I. Ilin, S. Shirokova, MATEC Web of Conferences 193 (2018)

7. Creation of a self-organizing innovation ecosystem in zones of special territorial development, https://eee-region.ru/article/5206/

8. Birth corporate ecosystems, https://innopraktika.ru/upload/report.pdf

9. Stages of the development of the system approach in the management of product quality, the domestic experience in the formation of quality systems - Commodity management, https://testmyprep.com/

10. I.V. Ilin, D.D. Bolobonov, A.K. Frolov, Proceedings of the 33rd International Business Information Management Association Conference, IBIMA 2019: Education Excellence and Innovation Management through Vision 2020, 5092-5102 (2019)

11. A. Ivanov, I. Shustova, Creative economy 5 (2020)

12. H. Lebret, Start-up: What we may still learn from Silicon Valley (Create Space, 2007)

13. M. Kolloch, D. Dellermann, Technological Forecasting and Social Change 136 (2017) DOI: $10.1016 /$ j.techfore.2017.03.033

14. A. Gawer, Journal of Product Innovation Management 31(3) (2014) DOI: $10.1111 /$ jpim. 12105

15. Medicine innovations: new treatment technologies, problems, and solutions, https://belhope.ru/napravleniyamediciny/innovacionnaya-medicina

16. Y. Cai, J. Ma, Sustainability 12(11), 4376 (2020) DOI: 10.3390/su12114376

17. N. Pavlov, S. Kalyazina, I. Bagaeva, V. Iliashenko, Advances in Intelligent Systems and Computing 1259 AISC, 143-157 (2021)

18. A. Dubgorn, M.N. Abdelwahab, A. Borremans, I. Zaychenko, Proceedings of the 33rd International Business Information Management Association Conference, IBIMA 2019: Education Excellence and Innovation Management through Vision 2020, $9677-$ 9682 (2019)

19. A.D. Borremans, I.M. Zaychenko, O.Y. Iliashenko, MATEC Web of Conferences (2018) https://doi.org/10.1051/matecconf/201817001034

20. H.W. Chesbrough, Open innovation: The new imperative for creating and profiting from technology (Mass, Harvard Business School Press, Boston, 2003)

21. M. Eekhout, Lectures on innovation in building technology (2015) DOI 10.3233/978-161499-556-2 
22. I.V. Ilin, A.V. Izotov, S.V. Shirokova et al, Proceedings of 2017 20th IEEE International Conference on Soft Computing and Measurements, SCM 2017 7970732, 812-814 (2017) DOI: 10.1109/SCM.2017.7970732

23. A.I. Levina, A.S. Dubgorn, O.Y. Iliashenko, Proceedings - 2017 European Conference on Electrical Engineering and Computer Science, EECS 2017, 351-355 (2018) DOI: 10.1109/EECS.2017.72

24. Approaches to defining and typing digital platforms, https://files.dataeconomy.ru/digital_platforms_project.pdf 